\title{
Editorial: Never mind the gap: Gender-related research in Physical Review Physics Education Research, 2005-2016
}

Physical Review Physics Education Research recently published a Focused Collection on Gender in Physics. Publications in this Focused Collection indicate exciting new directions in physics education research. For example, one article, grounded in critical race theory, examines the lived experiences of six Black women physicists, including obstacles faced in their career paths and strategies used to overcome these obstacles [1]. Another documents physics graduate student experiences of sexism and gender microaggressions [2].

As a member of the Editorial Board of Physical Review Physics Education Research, I was curious to observe the history of publications in this journal relating to women, men, or gender, as well as the history of publications relating to other social identities including race, sexuality, disability, and class. I conducted an analysis of gender-related research published before the Focused Collection. About 400 papers were published in the journal during that time (September 2005-July 2016); more details about my analysis and results can be found in the Supplemental Material [3]. Few papers in this period address questions related to gender (7\%) and most of those that do focus on performance gaps (80\%). Very few papers address questions relating to race, ethnicity, class, sexuality, disability status, or other social identities (3\%). I am hopeful that this Focused Collection will educate physics education researchers about feminist issues, and provide both the foundation and the stimulus for new research directions.

Published 30 November 2016

Rachel Scherr

Department of Physics

Seattle Pacific University

Seattle, Washington 98119, USA

DOI: 10.1103/PhysRevPhysEducRes.12.020003

[1] K. Rosa and F. M. Mensah, Educational pathways of Black women physicists: Stories of experiencing and overcoming obstacles in life, Phys. Rev. Phys. Educ. Res. 12, 020113 (2016).

[2] R. S. Barthelemy, M. McCormick, and C. Henderson, Gender discrimination in physics and astronomy: Graduate student experiences of sexism and gender microaggressions, Phys. Rev. Phys. Educ. Res. 12, 020119 (2016).

[3] See Supplemental Material at http://link.aps.org/ supplemental/10.1103/PhysRevPhysEducRes.12.020003 for details. 